National Marine

Fisheries Service

NOAA
Fishery Bulletin

as established in 1881 ๙
Spencer F. Baird

First U.S. Commissioner of Fisheries and founder of Fishery Bulletin

\begin{abstract}
Spiny dogfish (Squalus acanthias) are traditionally aged by counting band pairs on dorsal-fin spines; however, wear and tear of the spines make obtaining accurate age estimates of older spiny dogfish difficult. Vertebral centra are an alternate structure that can be used to estimate age, but success in their use has been varied. We conducted a tag-recapture study using oxytetracycline injections to validate annual deposition in both dorsal-fin spines and vertebral centra of spiny dogfish. When band pairs in vertebral centra were used, time at liberty was significantly underestimated. Additionally, band-pair counts were found to change along the vertebral column of an individual, further refuting the use of vertebral centra to generate age estimates. Band-pair deposition in dorsal-fin spines was confirmed to be annual in spiny dogfish at liberty for up to 2.6 years. Dorsal-fin spines should continue to be used to age spiny dogfish, and vertebral centra are not a viable alternative.
\end{abstract}

\section{Validation of the use of vertebrae and dorsal-fin spines for age determination of spiny dogfish (Squalus acanthias) in the western North Atlantic Ocean}

\author{
Kelsey C. James (contact author) ${ }^{1}$ \\ Lisa J. Natanson ${ }^{1}$ \\ Christopher Flight ${ }^{2}$
}

\author{
Cindy Tribuzio ${ }^{3}$ \\ John Hoey ${ }^{1}$ \\ Camilla McCandless ${ }^{1}$
}

Email address for contact author: kelsey.james@noaa.gov

${ }^{1}$ Northeast Fisheries Science Center
National Marine Fisheries Service, NOAA
28 Tarzwell Drive
Narragansett, Rhode Island 02882
Present address for contact author: Southwest
Nationa
8901 La
La Jolla,
${ }^{2}$ Dauphin Island Sea Lab
101 Bienville Boulevard
Dauphin Island, Alabama 36528
${ }^{3}$ Alaska Fisheries Science Center
National Marine Fisheries Service, NOAA
17109 Point Lena Loop Road
Juneau, Alaska 99801

Spiny dogfish (Squalus acanthias) range from Labrador, Canada, to Florida in the western North Atlantic Ocean but are most common from Nova Scotia, Canada, to Cape Hatteras, North Carolina (Collette and Klein-MacPhee, 2002). In the western North Atlantic Ocean, spiny dogfish have been landed in commercial fisheries on a small scale since the 1930s (Rago and Sosebee, 2009). Landings of spiny dogfish soared in the 1970 s until foreign fishing ceased in 1977 , when the Fishery Conservation and Management Act of 1976 became effective (Fishery...2018), and spiny dogfish were declared "underutilized" by the late 1980s (Rago and Sosebee, 2009; DFO, 2020). In the United States, a large-scale directed fishery targeting mature females began in the $1990 \mathrm{~s}$, resulting in a significant reduction in female spawning stock biomass (NEFSC, 1998). In Canada, smaller scale directed fishing during 1998-2008 targeted mostly adult males with a mix of juvenile males and mature females (DFO, 2020). The population of spiny dogfish in the western North Atlantic Ocean was declared overfished in 1998 (NEFSC, 1998). Effective management practices led to population rebuilding, and as of the stock assessment completed in 2006, spiny dogfish in the western North Atlantic Ocean are no longer considered overfished and no overfishing has been occurring (NEFSC, 2006). These stock assessments rely on accurate life history characteristics, including validated age and growth. 
Age determination for the spiny dogfish and its closely related congeneric species, the Pacific spiny dogfish (S. suckleyi) has been studied extensively. Note that, until 2010, S. suckleyi was considered the same species as $S$. acanthias (Ebert et al., 2010; Veríssimo et al., 2010), and many studies did not distinguish between the 2 species. For the purposes of this paper, however, spiny dogfish refers only to $S$. acanthias. Both species have been aged since at least the 1930s, through the use of a variety of methods (Kaganovskaia, 1933; Holden and Meadows, 1962; Jensen, 1965; Ketchen, 1975; Jones and Geen ${ }^{1}$; Nammack et al., 1985; McFarlane and Beamish, 1987; Saunders and McFarlane, 1993; Campana et al., 2006, 2009; McFarlane and King, 2009; Tribuzio et al., 2010; Bubley et al., 2012; Tribuzio et al., 2017). The use of dorsal-fin spines has long been considered the standard for age determination of spiny dogfish because early researchers were unable to elucidate band pairs in vertebrae (Kaganovskaia, 1933; Tribuzio et al., 2016). The use of fin spines, meanwhile, has the issue of wear that obscures or eliminates growth bands and requires the use of correction factors that may or may not be suitable (Ketchen, 1975; Taylor et al., 2013).

Over time, improvements in the ability to enhance band pairs led to attempts at age determination with vertebrae because the use of these structures did not require correction factors. This development has allowed comparisons between band-pair counts of dorsal-fin spines and vertebral centra (Bubley et al., 2012; Tribuzio et al., 2017). Bubley et al. (2012) concluded that use of vertebral counts resulted in more reliable and accurate age estimates that produced biologically appropriate growth parameters for spiny dogfish than the variable ages from the use of dorsalfin spines that requires correction factors to account for lost annuli from wear. On the other hand, Tribuzio et al. (2017) found vertebral counts underestimated counts of unworn dorsal-fin spines of Pacific spiny dogfish over 10 years old.

Compounding the decision of what structure to use to age spiny dogfish are various age validation studies. In a reevaluation of data from early studies (McFarlane and Beamish, 1987) that used oxytetracycline (OTC) on dorsal-fins spines of Pacific spiny dogfish at liberty for up to 20 years, the band pairs on the dorsal-fin spines were considered annual. However, in 3 individuals at liberty for 20-21 years, 7-18 band pairs were missing (McFarlane and King, 2009). Campana et al. (2006) validated ages of spiny dogfish from the region of the western North Atlantic Ocean in Canada, using bomb radiocarbon techniques, and determined that band-pair formation in dorsal-fin spines was annual up to at least 25 years. Neither Bubley et al. (2012) nor Tribuzio et al. (2017) validated band-pair deposition in vertebral centra, but in both studies marginal increment analysis was used and results indicate annual periodicity in band-pair formation

\footnotetext{
${ }^{1}$ Jones, B. C., and G. H. Geen. 1977. Age and growth of spiny dogfish (Squalus acanthias) in the Strait of Georgia, British Columbia. Fish. Mar. Serv., Tech. Rep. 699, 16 p. [Available from website.]
}

in vertebral centra. Given the importance of age estimates in stock assessment, it is vital to validate the age determination methods.

Appropriate stock assessment and management rely on accurate age determinations for spiny dogfish because these ages facilitate calculation of growth, mortality, age at maturity, and longevity estimates. In view of the history of the spiny dogfish fishery, and the need for accurate biological information for management, an intensive cooperative research program was initiated by NOAA to obtain detailed life history data. This paper reports on one portion of this program, specifically, the use of vertebrae and dorsal-fin spines to determine age and growth. The primary goal of this study was to attempt to validate the periodicity in formation of band pairs in vertebral centra of spiny dogfish by using individuals injected with OTC. Of secondary importance for this work was confirming validation of annual band-pair deposition in dorsal-fin spines of this species.

\section{Materials and methods}

\section{Tagging and sample collection}

Sampling cruises were conducted by 3 vessels in the Gulf of Maine, on Georges Bank, and off southern New England 5 times: in February 2011, in July 2011, in November and December 2011, in July and August 2012, and in November and December 2012. Spiny dogfish were collected during 20-min tows of otter trawls. During sampling in 2011 , the first 5 spiny dogfish out of every 25 brought on board were selected for injection with OTC; however, in 2012, only the first 5 individuals from each tow were selected for injection with OTC. Straight-line fork length (FL), total length (TL), and stretch total length (STL) to the nearest millimeter, weight to the nearest $0.05 \mathrm{~kg}$, and sex were recorded. Oxytetracycline was injected intramuscularly into each spiny dogfish at a dosage of $25 \mathrm{mg}$ of OTC per kilogram of body weight (Holden and Vince, 1973). A rototag (Dalton ID Ltd. ${ }^{2}$, Henley-on-Thames, UK) was then attached to the first dorsal fin before release (Kohler and Turner, 2001).

Recaptured sharks were returned whole to the Narragansett Laboratory of the NOAA Northeast Fisheries Science Center. All specimens were frozen prior to examination. Spiny dogfish were measured (FL, TL, and STL) and weighed. Whole vertebral columns and the second dorsal-fin spine were extracted for age validation.

\section{Validation of ages from vertebrae and dorsal-fin spines}

For consistency, vertebrae 19-23, which are among the largest vertebrae, were removed from each specimen of spiny dogfish. Only vertebrae from individuals with

\footnotetext{
${ }^{2}$ Mention of trade names or commercial companies is for identification purposes only and does not imply endorsement by the National Marine Fisheries Service, NOAA.
} 
times at liberty (TAL) greater than 1 year were used for validation. From each specimen, 1 centrum was processed for band-pair count (hereafter referred to as the histology section) and 1 centrum was processed for OTC mark analysis (hereafter referred to as the OTC section). The histology section was processed by using thin sectioning methods to enhance the band pairs following Natanson et al. (2007). The OTC section was embedded in TAP Clear-Lite casting resin (TAP Plastics, San Leandro, CA) and sectioned through the frontal plane with an IsoMet Low Speed Saw (Buehler, Lake Bluff, IL) by using paired diamond-edged blades separated by a 0.6-mm spacer. Sections were stored individually in capsules in $70 \%$ ethanol and kept in the dark to preserve the OTC mark. Two photographs of the OTC section were taken under reflected light by using 1) white light and 2) long-wave ultraviolet light (366 nm) with a Nikon DSRi2 digital camera (Nikon Corp., Tokyo, Japan) attached to a Nikon SMZ1500 stereomicroscope (Nikon Instruments Inc., Melville, NY). The number of band pairs (consisting of 1 opaque and 1 translucent band) distal to the OTC mark was counted.

The distance from OTC mark to the centrum edge was measured in Adobe Photoshop CC 2017 (Adobe Inc., San Jose, CA) on the OTC section and transferred to the histology section to determine the location of the OTC mark relative to the band pairs. Because of the slight differences in sizes of adjacent vertebra, a ratio was used to calculate the position of the OTC mark on the histology section (Natanson, 1993). Band pairs past the OTC mark were then counted on the histology section; a half of a band pair indicated that the OTC mark was in the ultimate band (either translucent or opaque).

Dorsal-fin spines were removed, scraped clean of excess tissue, and thoroughly dried. Digital images of the dried second dorsal-fin spines with OTC marks regardless of TAL were photographed by using an MTI CCD-72 video camera (Dage-MTI Inc., Michigan City, IN) attached to an SZX9 Olympus stereomicroscope (Olympus Corp., Tokyo, Japan) with long-wave ultraviolet light (366 nm). The OTC image was then superimposed over an identical image taken under reflected white light by using Adobe Photoshop CC 2017. Band pairs past the OTC mark were then counted.

Linear regressions were performed on the data from each structure to determine if band-pair deposition was annual. Annual deposition is supported if the slope of the regression of the number of band pairs past the OTC mark against the TAL is not significantly different from 1 (i.e., the $95 \%$ confidence interval [CI] overlaps 1). Linear regressions were calculated for data from the vertebral centra and the dorsal-fin spines in $\mathrm{R}$, vers. 3.4.4 ( $\mathrm{R}$ Core Team, 2018).

\section{Vertebral column analysis}

For preliminary analysis of the whole vertebral column, one adult female spiny dogfish $(87.0 \mathrm{~cm} \mathrm{FL})$ was collected separately in 2019 to compare the number of band pairs among centra along the vertebral column. This individual was not one of the recaptured individuals because a fresh, large individual was desired, and it was needed to avoid any potential shrinkage of the vertebrae during prolonged frozen storage. Fork length, TL, STL, weight, sex, and maturity status were recorded. Vertebra numbers 1-80 from the head to the tail were measured to the nearest $0.1 \mathrm{~mm}$ in 3 dimensions: dorsoventral diameter (hereafter referred to as dorsal), lateral diameter (hereafter referred to as lateral), and rostrocaudal length (hereafter referred to as length). Each measurement was plotted against centrum number to observe changes in vertebral shape along the vertebral column. To determine if the number of band pairs varied along the vertebral column, every fifth vertebra was processed histologically and band pairs were counted as outlined above. No assumptions were made about the birth date of spiny dogfish; therefore, only whole band pairs are reported for this analysis. The band-pair count also was plotted by centrum number. The mean band-pair count and $95 \% \mathrm{CI}$ of the mean were calculated among centra for the vertebral column. If the band-pair counts of more than $5 \%$ of the centra examined were outside of the calculated $95 \%$ CI, the band-pair counts differed significantly along the vertebral column (James and Natanson, 2020).

\section{Results}

\section{Tagging and sample collection}

A total of 4306 spiny dogfish were injected with OTC, tagged, and released. Between July 2011 and September 2016, 148 spiny dogfish were recaptured and returned whole to the Narragansett Laboratory. No OTC-injected spiny dogfish were returned after 2016. Time at liberty ranged from $1 \mathrm{~d}$ to 4.8 years. Eighty-seven individuals had TALs greater than 1 year; an OTC mark was observed in the vertebrae of 41 of these individuals (47.1\%; 33 females and 9 males). Out of the 148 dorsal-fin spines examined, 45 spines had an OTC mark $(30.4 \%$; 40 females and 5 males). All 45 dorsal-fin spines with an OTC mark were included in analysis regardless of TAL to increase the sample size. Twenty-one individuals had an OTC mark in both the vertebrae and the dorsal-fin spine (Fig. 1). The size range of all examined individuals was $51.5-87.5 \mathrm{~cm}$ FL at tagging and 52.8-87.3 $\mathrm{cm}$ FL at recapture (Tables 1 and 2). Some individuals shrank in FL over time, and this reduction in size is an artifact of the combination of small inaccuracies from measuring live spiny dogfish at capture and from measuring the recaptured spiny dogfish after being frozen.

\section{Validation of ages from vertebrae and dorsal-fin spines}

The number of band pairs past the OTC mark in vertebral centra does not support annual periodicity of band-pair formation. Vertebral centra had $0.5-2.5$ band pairs past 


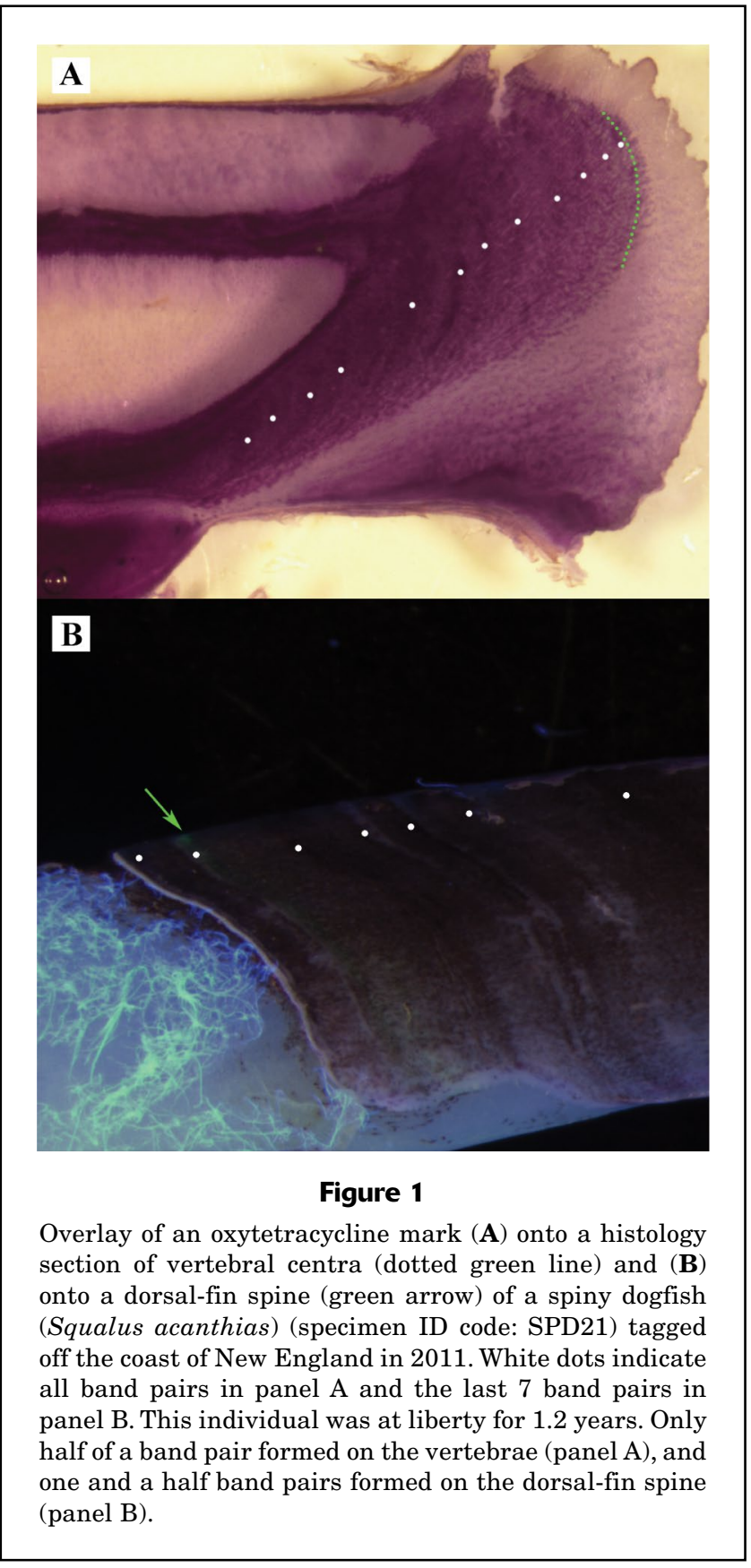

the OTC mark for spiny dogfish at liberty for 1.1-4.8 years (Table 1). Fewer band pairs were consistently seen than would be expected if band pairs were annual (Fig. 2). The slope of the line at 0.126 (95\% CI: $-0.078-0.330)$ is significantly different from the 1:1 reference line, confirming that, when vertebral band pairs were used, TAL was consistently underestimated.

Dorsal-fin spines had $0.5-3.5$ band pairs past the OTC mark for spiny dogfish at liberty for $0.1-2.6$ years (Table 2). In contrast to that for vertebrae, the number of band pairs past the OTC mark in dorsal-fin spines did confirm annual periodicity of band-pair formation (Table 2,
Fig. 2). Annual periodicity is supported, and the regression slope of 0.786 (95\% CI: $0.558-1.013)$ is not significantly different from the 1:1 reference line.

\section{Vertebral column analysis}

For the vertebral column analysis of one adult female, both centrum measurements and band-pair counts varied along the vertebral column. Vertebral band-pair counts roughly followed vertebral centra morphology (Fig. 3). The lowest band-pair count was observed in the vertebra directly behind the neurocranium (vertebra 1), and the highest count was found at vertebra 40 . Six of the 17 centra examined $(35.3 \%)$ had band-pair counts that fell outside of the 95\% CI (11.566-13.022) of the average band-pair count (12.294) along the entire vertebral column; therefore, the band-pair counts differed significantly along the vertebral column (Fig. 3).

\section{Discussion}

In this study, the results of OTC validation indicate that band pairs in vertebrae are not deposited annually in spiny dogfish. Use of counts of band pairs past the OTC mark consistently underestimated TAL for this species. Additionally, our results support previously published results indicating that band-pair deposition in fin spines is annual (Campana et al., 2006). On the basis of our results, we conclude that vertebrae are not an appropriate structure to use to estimate age for spiny dogfish.

Using a more detailed method, we were able to also obtain distinct band pairs in the vertebral centra of spiny dogfish. However, because of the prevalent underestimation of age observed from the location of the OTC mark within vertebral centra, we cannot recommend this structure for age determination of this species. These results are consistent with a growing number of studies with findings that indicate that vertebral band pairs do not accurately reflect age in sharks throughout their lives (see Harry, 2018; Natanson et al., 2018). In an attempt to understand the deposition of band pairs, Natanson et al. (2018) investigated the morphology and band-pair counts along the vertebral columns of several shark species and found that, in each species, band-pair counts varied along the vertebral column in relationship to vertebral size, not time, indicating a structural component to the band pairs. In our study, we found the same variation in band-pair counts along the vertebral column of a spiny dogfish. As per the species in the Natanson et al. (2018) study, lower band-pair counts were associated with smaller centra, indicating that band pairs are also related to the structure of the vertebra rather than to time in this species. Additionally, if band pairs were deposited annually, the same band-pair counts would be expected for every vertebra within an individual (Natanson et al., 2018). Although this finding for spiny dogfish is interesting, it is based on one specimen, and further work on more specimens of this species 


\section{Table 1}

Tag-recapture data and band-pair counts for the 41 recaptured spiny dogfish (Squalus acanthias) that had a time at liberty (TAL) greater than 1 year and an oxytetracycline (OTC) mark in a vertebra. Specimens were tagged in the Gulf of Maine, on Georges Bank, and off southern New England during 2011 and 2012. Fork length at tagging (TFL), fork length at recapture (RFL), TAL, and other data are arranged by increasing TAL.

\begin{tabular}{|c|c|c|c|c|c|c|}
\hline $\begin{array}{l}\text { Specimen } \\
\text { ID code }\end{array}$ & Sex & $\begin{array}{l}\text { TFL } \\
(\mathrm{cm})\end{array}$ & $\begin{array}{l}\text { RFL } \\
(\mathrm{cm})\end{array}$ & Date tagged & $\begin{array}{c}\text { TAL } \\
\text { (years) }\end{array}$ & $\begin{array}{l}\text { No. of band } \\
\text { pairs past } \\
\text { OTC mark }\end{array}$ \\
\hline SPD411 & $\mathrm{F}$ & 67.0 & 69.9 & 3-Aug-2012 & 1.05 & 2.5 \\
\hline SPD73 & $\mathrm{F}$ & 73.0 & 73.2 & 16-Jul-2011 & 1.10 & 1.0 \\
\hline SPD40 & $\mathrm{F}$ & 76.0 & 76.6 & 12-Jul-2011 & 1.11 & 1.5 \\
\hline SPD50 & $\mathrm{F}$ & 61.0 & 68.1 & 14-Jul-2011 & 1.11 & 1.0 \\
\hline SPD36 & $\mathrm{F}$ & 71.0 & 73.8 & 17-Jul-2011 & 1.12 & 1.5 \\
\hline SPD12 & $\mathrm{F}$ & 87.5 & 87.3 & 13-Jul-2011 & 1.13 & 0.5 \\
\hline SPD54 & M & 72.0 & 70.0 & 16-Jul-2011 & 1.16 & 0.5 \\
\hline SPD46 & $\mathrm{F}$ & 77.0 & 77.2 & 13-Jul-2011 & 1.16 & 0.5 \\
\hline SPD90 & $\mathrm{F}$ & 80.0 & 79.6 & 16-Jul-2011 & 1.17 & 1.0 \\
\hline SPD21 & $\mathrm{F}$ & 73.0 & 74.7 & 17-Jul-2011 & 1.19 & 0.5 \\
\hline SPD81 & $\mathrm{F}$ & 72.4 & 73.0 & 27-Nov-2011 & 1.20 & 0.5 \\
\hline SPD72 & $\mathrm{F}$ & 77.5 & 77.6 & 17-Jul-2011 & 1.23 & 1.0 \\
\hline SPD88 & $\mathrm{F}$ & 79.8 & 77.9 & 12-Jul-2011 & 1.28 & 0.5 \\
\hline SPD75 & $\mathrm{F}$ & 78.0 & 76.9 & 13-Jul-2011 & 1.32 & 0.5 \\
\hline SPD80 & $\mathrm{F}$ & 74.0 & 74.7 & 16-Jul-2011 & 1.32 & 1.0 \\
\hline SPD76 & $\mathrm{F}$ & 70.0 & 74.3 & 17-Jul-2011 & 1.33 & 1.5 \\
\hline SPD31 & M & 66.0 & 67.5 & 14-Feb-2011 & 1.49 & 1.0 \\
\hline SPD45 & M & 58.7 & 57.0 & 10-Feb-2011 & 1.56 & 0.5 \\
\hline SPD14 & M & 67.5 & 65.8 & 11-Feb-2011 & 1.58 & 0.5 \\
\hline SPD116 & $\mathrm{F}$ & 77.4 & 77.1 & 27-Nov-2011 & 1.58 & 0.5 \\
\hline SPD414 & $\mathrm{F}$ & 82.1 & 83.2 & 2-Dec-2011 & 1.60 & 0.5 \\
\hline SPD437 & $\mathrm{F}$ & 75.0 & 76.7 & 12-Jul-2011 & 1.60 & 0.5 \\
\hline SPD409 & $\mathrm{F}$ & 75.0 & 75.5 & 1-Dec-2011 & 1.62 & 1.0 \\
\hline SPD418 & $\mathrm{F}$ & 79.0 & 79.4 & 2-Dec-2011 & 1.62 & 1.5 \\
\hline SPD435 & $\mathrm{F}$ & 73.0 & 75.4 & 15-Jul-2011 & 1.63 & 1.0 \\
\hline SPD408 & M & 64.9 & 63.7 & 26-Nov-2011 & 1.70 & 0.5 \\
\hline SPD788 & $\mathrm{F}$ & 72.0 & 70.0 & 4-Dec-2012 & 1.71 & 1.0 \\
\hline SPD443 & $\mathrm{F}$ & 70.0 & 71.8 & 5-Dec-2011 & 1.74 & 0.5 \\
\hline SPD428 & M & 65.2 & 64.4 & 2-Dec-2011 & 1.81 & 0.5 \\
\hline SPD427 & $\mathrm{F}$ & 77.0 & 76.9 & 27-Nov-2011 & 1.94 & 1.5 \\
\hline SPD410 & $\mathrm{F}$ & 75.0 & 76.9 & 13-Jul-2011 & 2.02 & 0.5 \\
\hline SPD426 & $\mathrm{F}$ & 75.0 & 75.7 & 2-Dec-2011 & 2.12 & 0.5 \\
\hline SPD430 & M & 68.0 & 67.5 & 16-Feb-2011 & 2.47 & 0.5 \\
\hline SPD252 & M & 51.5 & 52.8 & 16-Feb-2011 & 2.54 & 0.5 \\
\hline SPD415 & $\mathrm{F}$ & 80.0 & 79.8 & 16-Jul-2011 & 2.58 & 1.0 \\
\hline SPD253 & M & 65.2 & 63.5 & 17-Feb-2011 & 2.61 & 1.5 \\
\hline SPD422 & $\mathrm{F}$ & 73.0 & 74.2 & 16-Jul-2011 & 2.61 & 0.5 \\
\hline SPD439 & $\mathrm{F}$ & 76.0 & 76.9 & 16-Jul-2011 & 2.63 & 0.5 \\
\hline SPD787 & $\mathrm{F}$ & 76.0 & 75.5 & 16-Jul-2011 & 3.10 & 1.0 \\
\hline SPD789 & $\mathrm{F}$ & 76.0 & 73.3 & 16-Jul-2011 & 3.41 & 1.5 \\
\hline SPD792 & $\mathrm{F}$ & 79.0 & 80.9 & 1-Dec-2011 & 4.80 & 2.0 \\
\hline
\end{tabular}

and on specimens of Pacific spiny dogfish would lead to more robust conclusions.

The absence of an OTC mark in wild specimens in markrecapture studies is well-documented (e.g., Smith, 1984; McFarlane and Beamish, 1987). In our study, an OTC mark was not found in many recaptured individuals in either vertebral centra or dorsal-fin spines, with OTC marking success rates of $47.1 \%$ and $30.4 \%$, respectively. Other studies have had success rates for OTC marking in vertebrae ranging from $37.5 \%$ (Harry et al., 2013) to $100 \%$ 


\section{Table 2}

Tag-recapture data and counts of band pairs past the oxytetracycline (OTC) mark for the 45 recaptured spiny dogfish (Squalus acanthias) that had an OTC mark on a dorsal-fin spine. Specimens were tagged in the Gulf of Maine, on Georges Bank, and off southern New England during 2011 and 2012. Fork length at tagging (TFL), fork length at recapture (RFL), time at liberty (TAL), and other data are arranged by increasing TAL.

\begin{tabular}{|c|c|c|c|c|c|c|}
\hline $\begin{array}{l}\text { Specimen } \\
\text { ID code }\end{array}$ & Sex & $\begin{array}{l}\text { TFL } \\
(\mathrm{cm})\end{array}$ & $\begin{array}{l}\text { RFL } \\
(\mathrm{cm})\end{array}$ & Date tagged & $\begin{array}{c}\text { TAL } \\
\text { (years) }\end{array}$ & $\begin{array}{l}\text { No. of band } \\
\text { pairs past } \\
\text { OTC mark }\end{array}$ \\
\hline SPD68 & $\mathrm{F}$ & 65.0 & 65.4 & 3-Dec-2012 & 0.08 & 0.5 \\
\hline SPD34 & $\mathrm{F}$ & 78.2 & 78.6 & 31-Jul-2012 & 0.08 & 0.5 \\
\hline SPD66 & $\mathrm{F}$ & 77.0 & 77.6 & 4-Dec-2012 & 0.09 & 0.5 \\
\hline SPD69 & $\mathrm{F}$ & 77.0 & 77.4 & 30-Nov-2012 & 0.10 & 0.5 \\
\hline SPD52 & $\mathrm{F}$ & 74.6 & 73.3 & 5-Aug-2012 & 0.12 & 0.5 \\
\hline SPD29 & $\mathrm{F}$ & 77.5 & 76.5 & 1-Dec-2011 & 0.28 & 0.5 \\
\hline SPD71 & $\mathrm{F}$ & 67.8 & 67.1 & 6-Aug-2012 & 0.28 & 0.5 \\
\hline SPD429 & $\mathrm{F}$ & 74.0 & 72.3 & 1-Dec-2012 & 0.41 & 0.5 \\
\hline SPD26 & $\mathrm{F}$ & 83.0 & 83.5 & 1-Dec-2011 & 0.42 & 0.5 \\
\hline SPD56 & $\mathrm{F}$ & 72.0 & 71.5 & 15-Jul-2011 & 0.48 & 0.5 \\
\hline SPD30 & $\mathrm{F}$ & 76.0 & 74.1 & 28-Nov-2011 & 0.59 & 0.5 \\
\hline SPD41 & $\mathrm{F}$ & 77.0 & 79.3 & 28-Nov-2011 & 0.65 & 0.5 \\
\hline SPD438 & $\mathrm{F}$ & 82.4 & 83.5 & 1-Aug-2012 & 0.74 & 0.5 \\
\hline SPD48 & M & 65.0 & 65.1 & $26-N o v-2011$ & 0.75 & 0.5 \\
\hline SPD17 & $\mathrm{F}$ & 76.2 & 78.2 & 25-Nov-2011 & 0.75 & 0.5 \\
\hline SPD43 & $\mathrm{F}$ & 72.0 & 73.0 & 27-Nov-2011 & 0.78 & 1.5 \\
\hline SPD15 & M & 65.0 & 65.5 & 25-Nov-2011 & 0.82 & 0.5 \\
\hline SPD24 & $\mathrm{F}$ & 76.7 & 77.3 & 16-Jul-2011 & 0.90 & 1.5 \\
\hline SPD23 & $\mathrm{F}$ & 80.0 & 79.4 & 13-Jul-2011 & 1.00 & 1.0 \\
\hline SPD411 & $\mathrm{F}$ & 67.0 & 69.9 & 3-Aug-2012 & 1.05 & 1.0 \\
\hline SPD44 & $\mathrm{F}$ & 71.0 & 74.3 & 12-Jul-2011 & 1.09 & 1.5 \\
\hline SPD40 & $\mathrm{F}$ & 76.0 & 76.6 & 12-Jul-2011 & 1.11 & 1.5 \\
\hline SPD50 & $\mathrm{F}$ & 61.0 & 68.1 & 14-Jul-2011 & 1.11 & 2.0 \\
\hline SPD36 & $\mathrm{F}$ & 71.0 & 73.8 & 17-Jul-2011 & 1.12 & 1.5 \\
\hline SPD12 & $\mathrm{F}$ & 87.5 & 87.3 & 13-Jul-2011 & 1.13 & 1.0 \\
\hline SPD417 & $\mathrm{F}$ & 76.0 & 76.1 & 16-Jul-2011 & 1.15 & 2.0 \\
\hline SPD46 & $\mathrm{F}$ & 77.0 & 77.2 & 13-Jul-2011 & 1.16 & 1.0 \\
\hline SPD21 & $\mathrm{F}$ & 73.0 & 74.7 & 17-Jul-2011 & 1.19 & 1.5 \\
\hline SPD75 & $\mathrm{F}$ & 78.0 & 76.9 & 13-Jul-2011 & 1.32 & 1.0 \\
\hline SPD76 & $\mathrm{F}$ & 70.0 & 74.3 & 17-Jul-2011 & 1.33 & 2.0 \\
\hline SPD14 & M & 67.5 & 65.8 & 11-Feb-2011 & 1.58 & 1.0 \\
\hline SPD116 & $\mathrm{F}$ & 77.4 & 77.1 & 27-Nov-2011 & 1.58 & 2.5 \\
\hline SPD414 & $\mathrm{F}$ & 82.1 & 83.2 & 2-Dec-2011 & 1.60 & 2.0 \\
\hline SPD437 & $\mathrm{F}$ & 75.0 & 76.7 & 12-Jul-2011 & 1.60 & 1.0 \\
\hline SPD409 & $\mathrm{F}$ & 75.0 & 75.5 & 1-Dec-2011 & 1.62 & 1.0 \\
\hline SPD436 & $\mathrm{F}$ & 73.0 & 75.1 & 12-Jul-2011 & 1.62 & 2.5 \\
\hline SPD418 & $\mathrm{F}$ & 79.0 & 79.4 & 2-Dec-2011 & 1.62 & 1.0 \\
\hline SPD408 & M & 64.9 & 63.7 & $26-N o v-2011$ & 1.70 & 1.0 \\
\hline SPD788 & $\mathrm{F}$ & 72.0 & 70.0 & 4-Dec-2012 & 1.71 & 1.0 \\
\hline SPD420 & $\mathrm{F}$ & 78.0 & 76.6 & 2-Dec-2011 & 1.93 & 1.0 \\
\hline SPD427 & $\mathrm{F}$ & 77.0 & 76.9 & 27-Nov-2011 & 1.94 & 2.0 \\
\hline SPD413 & $\mathrm{F}$ & 77.0 & 79.9 & 16-Jul-2011 & 1.97 & 1.5 \\
\hline SPD426 & $\mathrm{F}$ & 75.0 & 75.7 & 2-Dec-2011 & 2.12 & 2.0 \\
\hline SPD252 & M & 51.5 & 52.8 & $16-F e b-2011$ & 2.54 & 3.5 \\
\hline SPD422 & $\mathrm{F}$ & 73.0 & 74.2 & 16-Jul-2011 & 2.61 & 2.0 \\
\hline
\end{tabular}




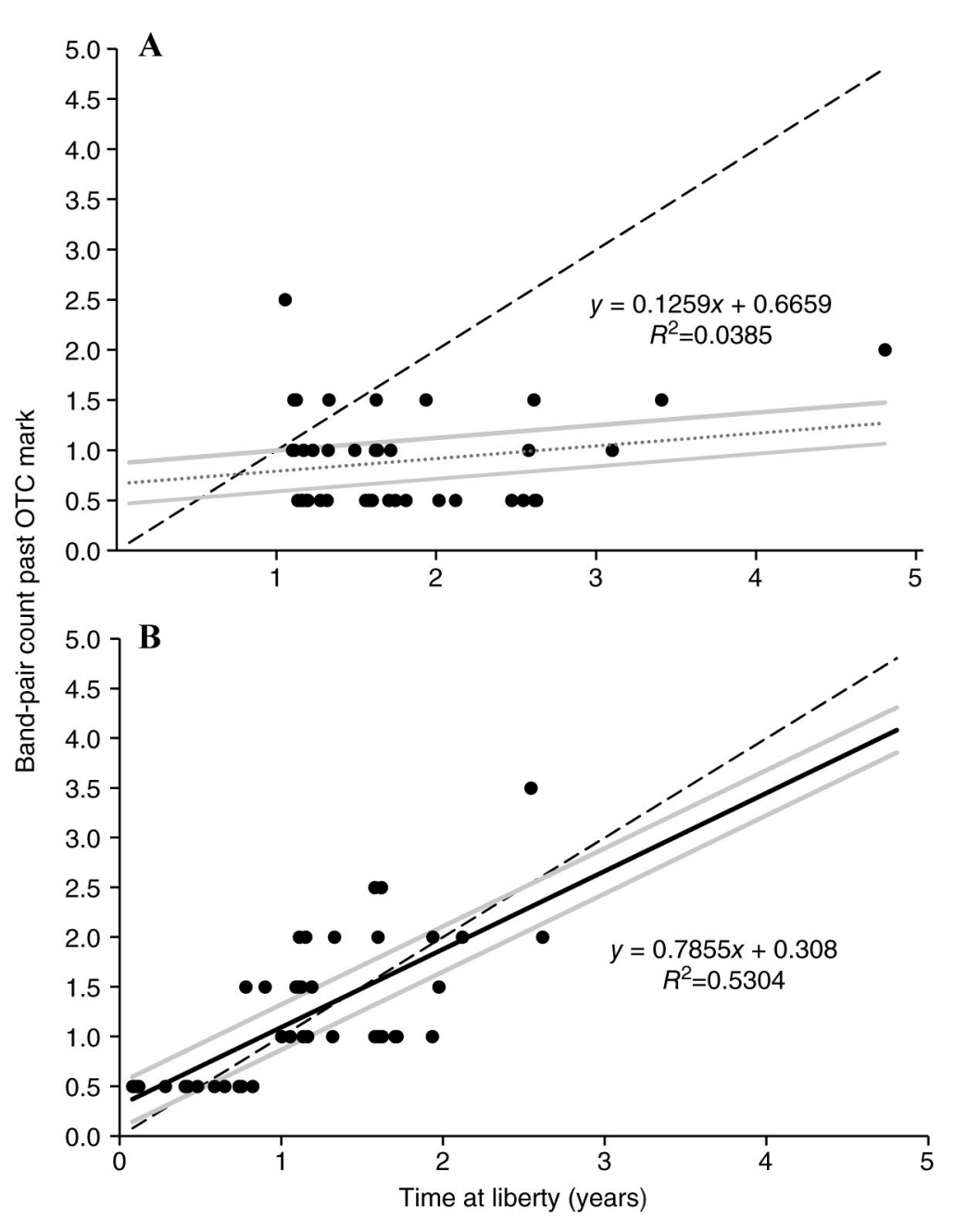

Figure 2

Relationship of time at liberty and the number of band pairs past the oxytetracycline (OTC) mark in the (A) vertebrae and (B) dorsal-fin spines of spiny dogfish (Squalus acanthias) tagged in the Gulf of Maine, on Georges Bank, and off southern New England during 2011 and 2012. The dotted line in panel A and the solid line in panel B indicate linear regressions. The $95 \%$ confidence intervals (CIs) of the slope of the linear regressions (gray lines) do not include a 1:1 relationship (dashed line) in panel A (95\% CI: -0.078-0.330) and do include a 1:1 relationship (dashed line) in panel B (95\% CI: $0.558-1.013) . R^{2}=$ coefficient of multiple determination.

One explanation for the absence of an OTC mark is insufficient mineralization directly after injection (Smith, 1984). Mineralization may slow seasonally (Jones and Geen, 1977) and with ontogeny (Francis et al., 2007; Natanson et al., 2018). In our study, spiny dogfish were injected with OTC in several seasons, but there were few recaptured individuals with OTC marks that had been injected in February (Tables 1 and 2). Similar results were reported by McFarlane and Beamish (1987), who found that OTC marks were visible at a higher rate in the dorsal-fin spines of spiny dogfish injected in the fall than in the spines of those injected in the spring. The low growth rates observed in our study and the generally large sizes of specimens (Tables 1 and 2) support the idea of slowed body growth and subsequently slowed mineralization, particularly for vertebrae (Francis et al., 2007, Natanson et al., 2018). Such small changes in growth compounded with inaccuracies from measuring live then frozen spiny dogfish could have resulted in the negative growth observed in our study. With the environmental and ontogenetic effects on mineralization and growth, low OTC marking success rates are not unexpected.

Age information is important for stock assessments intended to inform fisheries management. We investigated validation of annual deposition of band pairs in vertebral centra from spiny dogfish because of concerns over the effect on age estimates of wear and tear on dorsalfin spines. Although band pairs on vertebral centra are distinct, the results of our study from the use of chemical marking indicate that band pairs are not deposited annually and, therefore, that use of band pairs on this structure underestimates age in spiny dogfish. In contrast, validation of the use of dorsal-

(e.g., McAuley et al., 2006). Fewer studies have examined OTC deposition in dorsal-fin spines, but McFarlane and Beamish (1987) reported an OTC marking success rate of $34 \%$. There has not been a direct comparison of OTC marking success rates between vertebral centra and dorsal-fin spines; therefore, it cannot be known if rates differ between structures. However, the success rate for OTC marking was lower in dorsal-fin spines than in vertebrae in our study and was similar to that reported by McFarlane and Beamish (1987). This result indicates that dorsal-fin spines may incorporate OTC less readily than vertebral centra. fin spines is supported by our findings. Therefore, despite their limitations, fin spines are more representative of age than vertebrae in spiny dogfish.

\section{Acknowledgments}

We thank the Northeast Cooperative Research Program of the NOAA Northeast Fisheries Science Center, B. Gervelis, D. McElroy, and the fishermen that helped tag and recapture the spiny dogfish used in this study. We thank K. Wooley for helping process samples in the lab. 


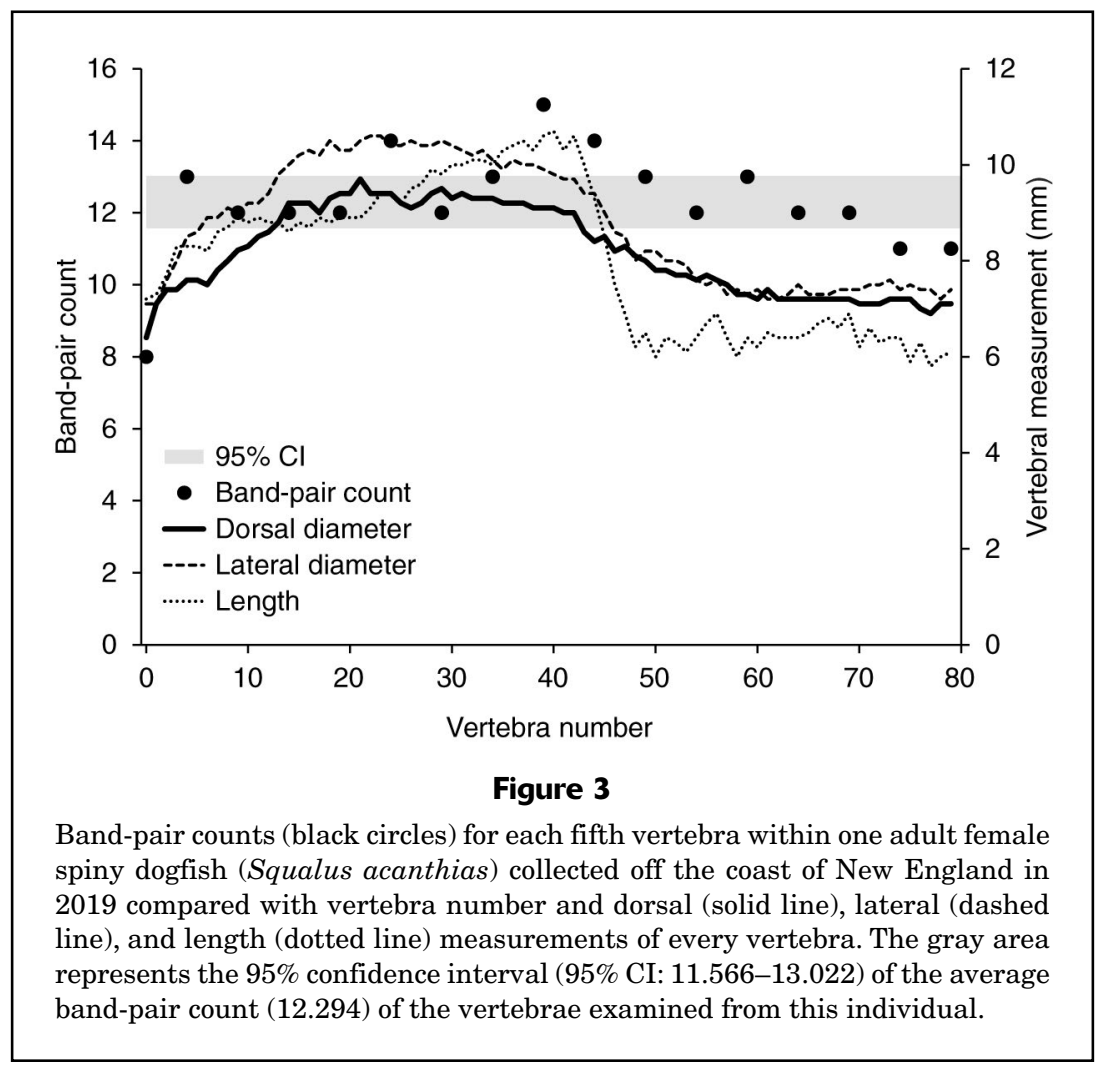

\section{Literature cited}

Bubley, W. J., J. Kneebone, J. A. Sulikowski, and P. C. W. Tsang. 2012. Reassessment of spiny dogfish Squalus acanthias age and growth using vertebrae and dorsal-fin spines. J. Fish Biol. 80:1300-1319. Crossref

Campana, S. E., C. Jones, G. A. McFarlane, and S. Myklevoll.

2006. Bomb dating and age validation using the spines of spiny dogfish (Squalus acanthias). Environ. Biol. Fishes 77:327-336. Crossref

Campana, S. E., W. Joyce, and D. W. Kulka.

2009. Growth and reproduction of spiny dogfish off the eastern coast of Canada, including inferences on stock structure. In Biology and management of dogfish sharks (V. F. Gallucci, G. A. McFarlane, and G. G. Bargmann, eds.), p. 195-208. Am. Fish. Soc., Bethesda, MD.

Collette, B. B., and G. Klein-MacPhee (eds.).

2002. Bigelow and Schroeder's fishes of the Gulf of Maine, 3rd ed., 748 p. Smithsonian Inst. Press, Washington, DC.

DFO (Fisheries and Oceans Canada).

2020. Assessment of Spiny Dogfish in the Northwest Atlantic. DFO Can. Sci. Advis. Sec. Sci. Advis. Rep. 2020/001. [Available from website.]

Ebert, D. A., W. T. White, K. J. Goldman, L. J. V. Compagno, T. S. Daly-Engel, and R. D. Ward.

2010. Resurrection and redescription of Squalus suckleyi (Girard, 1854) from the North Pacific, with comments on the Squalus acanthias subgroup (Squaliformes: Squalidae). Zootaxa 2612:22-40. Crossref

Fishery Conservation and Management Act of 1976. 16 U.S. Code 1801-1882 (2018). [Available from website.]

Francis, M. P., S. E. Campana, and C. M. Jones.

2007. Age under-estimation in New Zealand porbeagle sharks (Lamna nasus): is there an upper limit to ages that can be determined from shark vertebrae? Mar. Freshw. Res. 58:10-23. Crossref

Harry, A. V.

2018. Evidence for systemic age underestimation in shark and ray ageing studies. Fish Fish. 19:185-200. Crossref

Harry, A. V., A. J. Tobin, and C. A. Simpfendorfer.

2013. Age, growth and reproductive biology of the spot-tail shark, Carcharhinus sorrah, and the Australian blacktip shark, C. tilstoni, from the Great Barrier Reef World Heritage Area, north-eastern Australia. Mar. Freshw. Res. 64:277-293. Crossref

Holden, M. J., and P. S. Meadows.

1962. The structure of the spine of the spur dogfish (Squalus acanthias L.) and its use for age determination. J. Mar. Biol. Assoc. U.K. 42:179-197. Crossref

Holden, M. J., and M. R. Vince.

1973. Age validation studies on the centra of Raja clavata using tetracycline. ICES J. Mar. Sci. 35:13-17. Crossref

James, K. C., and L. J. Natanson.

2020. Positional and ontogenetic variation in the vertebral centra morphology in five batoid species. Mar. Freshw. Res. Crossref Jensen, A. C.

1965. Life history of the spiny dogfish. Fish. Bull. 65:527-554. Jones, B. C., and G. H. Geen.

1977. Age determination of an elasmobranch (Squalus acanthias) by X-ray spectrometry. J. Fish. Res. Board Can. 34:44-48. Crossref

Kaganovskaia, S.

1933. A method of determining the age and the compositions of the catches of the spiny dogfish (Squalus acanthias L.). Vestn. Dalnevost. Fil. Akad. Nauk SSSR 1-3:139-141.

Ketchen, K. S.

1975. Age and growth of dogfish Squalus acanthias in British Columbia waters. J. Fish. Res. Board Can. 32:43-59. Crossref 
Kohler, N. E., and P. A. Turner.

2001. Shark tagging: a review of conventional methods and studies. Environ. Biol. Fishes 60:191-224. Crossref

McAuley, R. B., C. A. Simpfendorfer, G. A. Hyndes, R. R. Allison, J. A. Chidlow, S. J. Newman, and R. C. J. Lenanton.

2006. Validated age and growth of the sandbar shark, Carcharhinus plumbeus (Nardo 1827) in the waters off Western Australia. Environ. Biol. Fishes 77:385-400. Crossref

McFarlane, G. A., and R. J. Beamish.

1987. Validation of the dorsal spine method of age determination for spiny dogfish. In Age and growth of fish (R. C. Summerfelt and G. E. Hall, eds.), p. 287-300. Iowa State Univ. Press, Ames, IA.

McFarlane, G. A., and J. R. King.

2009. Re-evaluating the age determination of spiny dogfish using oxytetracycline and fish at liberty up to 20 years. In Biology and management of dogfish sharks (V. F. Gallucci, G. A. McFarlane, and G. G. Bargmann, eds.), p. 153-160. Am. Fish. Soc., Bethesda, MD.

Nammack, M. F., J. A. Musick, and J. A. Colvocoresses. 1985. Life history of spiny dogfish off the northeastern United States. Trans. Am. Fish. Soc. 114:367-376. Crossref

Natanson, L. J. 1993. Effect of temperature on band deposition in the little skate, Raja erinacea. Copeia 1993:199-206.

Natanson, L. J., J. A. Sulikowski, J. R. Kneebone, and P. C. Tsang. 2007. Age and growth estimates for the smooth skate, Malacoraja senta, in the Gulf of Maine. Environ. Biol. Fishes 80:293-308. Crossref

Natanson, L. J., G. B. Skomal, S. L. Hoffmann, M. E. Porter, K. J.

Goldman, and D. Serra.

2018. Age and growth of sharks: do vertebral band pairs record age? Mar. Freshw. Res. 69:1440-1452. Crossref

NEFSC (Northeast Fisheries Science Center).

1998. 26th Northeast regional stock assessment workshop (26th SAW): stock assessment review committee (SARC) consensus summary of assessments. Northeast Fish. Sci. Cent. Ref. Doc. 98-03, 283 p. [Available from website.]

2006. 43rd Northeast regional stock assessment workshop (43rd SAW): 43rd SAW assessment summary report. Northeast Fish. Sci. Cent. Ref. Doc. 06-14, 43 p. [Available from website.]
R Core Team.

2018. R: a language and environment for statistical computing. R Foundation for Statistical Computing, Vienna, Austria. [Available from website, accessed March 2018.]

Rago, P. J., and K. A. Sosebee.

2009. The agony of recovery: scientific challenges of spiny dogfish recovery programs. In Biology and management of dogfish sharks (V. F. Gallucci, G. A. McFarlane, and G. G. Bargmann, eds.), p. 343-372. Am. Fish. Soc., Bethesda, MD.

Saunders, M. W., and G. A. McFarlane.

1993. Age and length at maturity of the female spiny dogfish, Squalus acanthias, in the Strait of Georgia, British Columbia, Canada. Environ. Biol. Fishes 38:49-57. Crossref

Smith, S. E.

1984. Timing of vertebral-band deposition in tetracyclineinjected leopard sharks. Trans. Am. Fish. Soc. 113:308-313. Crossref

Taylor, I. G., V. Gertseva, and S. E. Matson.

2013. Spine-based ageing methods in the spiny dogfish shark, Squalus suckleyi: how they measure up. Fish. Res. 147:83-92. Crossref

Tribuzio, C. A., G. H. Kruse, and J. T. Fujioka.

2010. Age and growth of spiny dogfish (Squalus acanthias) in the Gulf of Alaska: analysis of alternative growth models. Fish. Bull. 108:119-135.

Tribuzio C. A., M. E. Matta, C. Gburski, N. Atkins, and W. Bubley. 2016. Methods for the preparation of Pacific spiny dogfish (Squalus suckleyi), fin spines and vertebrae and an overview of age determinations. Mar. Fish. Rev. 78(1-2):1-13.

Tribuzio, C. A., M. E. Matta, C. Gburski, C. Blood, W. Bubley, and G. H. Kruse.

2017. Are Pacific spiny dogfish lying about their age? A comparison of ageing structures for Squalus suckleyi. Mar. Freshw. Res. 69:37-47. Crossref

Veríssimo, A., J. R. McDowell, and J. E. Graves.

2010. Global population structure of the spiny dogfish Squalus acanthias, a temperate shark with an antitropical distribution. Mol. Ecol. 19:1651-1662. Crossref 